\title{
Effect of depolarization on striatal amino acid efflux in perinatal rats: an in vivo microdialysis study
}

\author{
Faye S. Silverstein M.D. and Bina Naik M.D. \\ Departments of Pediatrics and Neurology, University of Michigan, Ann Arbor, MI 48109 (U.S.A.)
}

(Received 8 November 1990; Revised version received 14 March 1991; Accepted 9 April 1991)

Key words: $\quad$ Microdialysis; Striatum; Amino acid; Depolarization; Perinatal; Glutamate; Taurine

\begin{abstract}
We used in vivo microdialysis to determine if infusion of depolarizing concentrations of potassium stimulated striatal excitatory amino acid (EAA) efflux in post-natal day (PND) 7 rats. Dialysis probes were perfused with $100 \mathrm{mM} \mathrm{KCl}$ for $60 \mathrm{~min}(n=6)$; EAA efflux was unaffected until $40-60$ min after onset of the infusion, when a trend towards increased EAA efflux was observed (glutamate $284 \pm 56 \%$ of baseline). In animals exposed to $8 \%$ oxygen $(n=7)$ before a more prolonged $(100 \mathrm{~min}) \mathrm{KCl}$ infusion, again over the first $40 \mathrm{~min}$ of $\mathrm{KCl}$ there were no changes in EAA efflux; subsequently, glutamate, aspartate and taurine efflux increased (peak values $682 \pm 187 \%, 228 \pm 32 \%$, and $1208 \pm 437 \%$ of baseline). These data suggest that in PND 7 rats a substantial contribution to basal striatal EAA efflux may be derived from non-neurotransmitter pools.
\end{abstract}

We recently developed a method for in vivo striatal microdialysis in post-natal day (PND) 7 Sprague-Dawley rats [8], which we have used to measure striatal extracellular fluid (ECF) amino acid efflux in immature rodent brain [16]. The ECF content of neurotransmitter amino acids presumably reflects synaptic release, in addition to release from neuronal metabolic pools, and from glia; however, the relative contributions of these three pools is difficult to delineate $[14,17,18]$. In mature experimental animals, in vivo microdialysis studies have demonstrated that severe hypoglycemia [3] and cerebral ischemia $[1,2,7,11]$ markedly increase ECF accumulation of excitatory amino acids (EAA); these increases may be attributable to suppression of neuronal and glial re-uptake and/or increased release (from neurotransmitter and/or metabolic pools) $[10,15]$.

In PND 7 rats, using microdialysis, we found that insulin-induced hypoglycemia stimulated glutamate and taurine efflux in striatum, but to a much lesser degree than that reported in adult brain, while aspartate efflux was unaffected [16]. In preliminary studies of hypoxiaischemia-induced alterations in striatal amino acid efflux, transient bursts of increased glutamate (and taurine) efflux [9], rather than the sustained marked elevations in glutamate and aspartate efflux reported in adult brain, were detected. These differences from patterns in adult brain stimulated us to further charac-

Correspondence: F.S. Silverstein, Room 6028, Kresge II, Box 0570, University of Michigan, Ann Arbor, MI 48109, U.S.A. terize striatal amino acid efflux at this developmental stage.

A practical strategy for assessment of the impact of the ionic milieu on neurotransmitter efflux is to alter the ionic composition of the microdialysis perfusion medium. We previously demonstrated that in PND 7 rats, microdialysis probe perfusion with solutions containing $100 \mathrm{mM}$ potassium chloride $(\mathrm{KCl})$, to elicit depolarization, markedly stimulated striatal dopamine efflux within 20 minutes [8]. In adult brain, both in vitro, in synaptosome preparations, and in vivo, depolarizing concentrations of $\mathrm{KCl}(30-100 \mathrm{mM})$ stimulate efflux of neurotransmitter amino acids from pre-synaptic nerve terminals, and from glia $[6,14,19]$. In this study, we determined the effects of $\mathrm{KCl}$-induced depolarization on striatal amino acid efflux at this developmental stage. Based on our observations that hypoxic exposure increased the magnitude of depolarization-evoked dopamine release [8], we also examined the impact of moderate hypoxia ( $8 \%$ oxygen) on striatal amino acid efflux.

Microdialysis probes were implanted into the right striatum of ether-anesthetized PND 7 Sprague-Dawley rats (landmarks referenced to bregma: AP $-1 \mathrm{~mm}, \mathrm{~L} 2.5$ $\mathrm{mm}, \mathrm{D} 5 \mathrm{~mm}$ [7]). Animals recovered for $2 \mathrm{~h}$ in warmed plastic containers (surface temperature maintained at $35.5^{\circ} \mathrm{C}$ ); brain temperature was not monitored. The microdialysis protocol was approved by the University of Michigan Committee on Use and Care of Animals. Only data from pups with histologically verified probe placement were evaluated (about $2 / 3$ animals). Probes were 
perfused with filtered modified Ringer's solution $(\mathrm{NaCl}$ $147 \mathrm{mM}, \mathrm{KCl} 4 \mathrm{mM}, \mathrm{CaCl}_{2} 3.4 \mathrm{mM}, \mathrm{pH} 7.2$ ) at $1.5 \mu \mathrm{l} /$ min (CMA 100 micro-infusion pump Bioanalytical Systems). To induce depolarization, a solution containing $100 \mathrm{mM} \mathrm{KCl}, 3.4 \mathrm{mM} \mathrm{CaCl}_{2}$ and $50 \mathrm{mM} \mathrm{NaCl}$ (to maintain isotonicity) was substituted. It must be noted that perfusion solutions were not oxygenated, and all samples collected from perfused striatum may, to some degree, have reflected local tissue hypoxia.

In preliminary experiments (data not shown), we were surprised to find that infusion of $\mathrm{KCl}(100 \mathrm{mM})$ for 20 30 min did not alter amino acid efflux. Two protocols were used to evaluate this response in greater detail. In the first group, 3 sequential $20 \mathrm{~min}$ baseline samples were collected in all pups $(n=12)$; then, probes were perfused with a solution containing $100 \mathrm{mM} \mathrm{KCl}$ and 3 more samples were obtained $(n=6) ; 3$ additional samples were also collected in controls $(n=6)$. In the second group, af-

\section{TABLE I}

STRIATAL AMINO ACID EFFLUX IN PND 7 RATS: EFFECTS OF PERFUSION WITH $100 \mathrm{mM} \mathrm{KCl}$

$n=6$ animals/group. \% Baseline: for each animal, the mean of the efflux values in the first 3 samples collected was calculated, and subsequent values were expressed as \% of this mean. Group means were calculated subsequently. After insertion of a microdialysis probe into the right striatum of PND 7 rats (see text for details of method), and a 2 $\mathrm{h}$ recovery period, 6 sequential $20 \mathrm{~min}$ dialysate fractions were collected and analyzed for amino acid content. In controls, probes were continuously perfused with a modified Ringer's solution. In the experimental group after collection of the third fraction, perfusion with a solution containing $100 \mathrm{mM} \mathrm{KCl}, 3.4 \mathrm{mMCaCl}_{2}$, and $50 \mathrm{mM} \mathrm{NaCl}$ was initiated, and fractions $4-6$ were collected.

\begin{tabular}{|c|c|c|c|c|}
\hline \multirow[t]{2}{*}{ Amino acid } & \multirow[t]{2}{*}{ Group } & \multicolumn{3}{|c|}{$\begin{array}{l}\text { Fraction no. } \\
\text { (\% baseline) }\end{array}$} \\
\hline & & 4 & 5 & 6 \\
\hline \multirow[t]{2}{*}{ Glutamate } & $\mathrm{KCl}$ & $75 \pm 12$ & $96 \pm 10$ & $284 \pm 56$ \\
\hline & Control & $91 \pm 20$ & $70 \pm 13$ & $161 \pm 62$ \\
\hline \multirow[t]{2}{*}{ Aspartate } & $\mathrm{KCl}$ & $61 \pm 19$ & $63 \pm 20$ & $140 \pm 60$ \\
\hline & Control & $71 \pm 13$ & $66 \pm 28$ & $94 \pm 24$ \\
\hline \multirow[t]{2}{*}{ Serine } & $\mathrm{KCl}$ & $89 \pm 2$ & $101 \pm 14$ & $107 \pm 14$ \\
\hline & Control & $93 \pm 8$ & $80 \pm 18$ & $83 \pm 26$ \\
\hline \multirow[t]{2}{*}{ Taurine } & $\mathrm{KCl}$ & $95 \pm 12$ & $105 \pm 9$ & $264 \pm 78$ \\
\hline & Control & $101 \pm 11$ & $105 \pm 8$ & $340 \pm 95$ \\
\hline \multirow[t]{2}{*}{ GABA } & $\mathrm{KCl}$ & $107 \pm 14$ & $131 \pm 28$ & $351 \pm 122$ \\
\hline & Control & $84 \pm 17$ & $112 \pm 22$ & $84 \pm 17$ \\
\hline \multirow[t]{2}{*}{ Glycine } & $\mathrm{KCl}$ & $72 \pm 12$ & $86 \pm 9$ & $115 \pm 20$ \\
\hline & Control & $107 \pm 12$ & $100 \pm 10$ & $159 \pm 59$ \\
\hline
\end{tabular}

ter 2 baseline samples were collected, animals were exposed to $8 \% \mathrm{O}_{2}(n=7)$ for $60 \mathrm{~min}$ before initiation of the $\mathrm{KCl}$ infusion. The $\mathrm{KCl}$ infusion was continued for $60 \mathrm{~min}$ in hypoxia and for an additional $40 \mathrm{~min}$ in room air; 10 sequential fractions were also collected from 3 untreated controls.

After a pre-column derivatization, samples were analyzed by HPLC $[5,16]$. Samples $(30 \mu 1)$ were mixed with $22.5 \mu \mathrm{l}$ of the derivatizing solution $(27 \mathrm{mg} o$-pthaldialdehyde / $2 \mathrm{ml} 100 \mathrm{mM}$ borax, with $20 \mathrm{ml}$ mercaptoethanol, pH 9.5) for 2 min before injection onto a $\mathrm{C} 18$ reverse phase column ( $5 \mu$ ODS, Altex); the mobile phase was $0.1 \mathrm{M} \mathrm{NaH}_{2} \mathrm{PO}_{4}, \mathrm{pH} 6.5$ with $35 \%$ methanol. A glassy carbon electrode connected to an electrochemical detector (Bioanalytical Systems) was used (sensitivity 20 nAmp, electrode potential $0.7 \mathrm{~V}$ vs $\mathrm{Ag} / \mathrm{AgCl}$ ). Glutamate, aspartate, glutamine, glycine, asparagine, taurine, serine, and alanine were consistently detected in dialysates; $\gamma$-aminobutyric acid (GABA) was detected intermittently. Values were quantified by measurement of peak heights, and comparison with peak heights of external standards.

Efflux values were expressed as \% of baseline. Baseline values were averaged from the first three dialysate samples in each animal, in the first group of experiments, and from the first two samples collected in the second group. Descriptive statistics, analysis of variance (ANOVA) for repeated measures, and Mann-Whitney $U$-tests were performed using a microcomputer based statistical package (Statview).

Absolute values for amino acid efflux were in the same range as previously reported $(1.5-2 \mathrm{pmol} / \mathrm{min}$ for glutamate and aspartate)[16]. In controls, amino acid efflux did not change over $3.5 \mathrm{~h}$ (Table I, Fig. 1). Initially, infusion of $100 \mathrm{mM} \mathrm{KCl}$ had no effect on amino acid efflux. Over the first $40 \mathrm{~min}$ of the infusion, in two sequential dialysate samples amino acid efflux remained stable; in the final sampling period, 40-60 min after initiation of the $\mathrm{KCl}$ infusion, mean efflux values for glutamate, taurine, and GABA were elevated to $>250 \%$ of baseline but there was considerable inter-animal variation (Table I; repeated measures ANOVA for each amino acid, values expressed as\% baseline, $P=$ n.s.).

With the second experimental protocol which included both hypoxic exposure and a longer $(100 \mathrm{~min})$ period of $\mathrm{KCl}$ infusion (Fig. 1), more consistent increases in glutamate, aspartate, and taurine release were detected. Exposure to $8 \% \mathrm{O}_{2}$ (Fig. 1, Fractions 2-4) did not alter glutamate, aspartate, or glutamine efflux, while taurine efflux rose 2- to 3-fold. As in the first group of experiments, in hypoxic animals, $\mathrm{KCl}$ infusion initially did not stimulate efflux (Fractions 5-6); however, again, from 40-60 min (Fraction 7), glutamate and aspartate efflux 

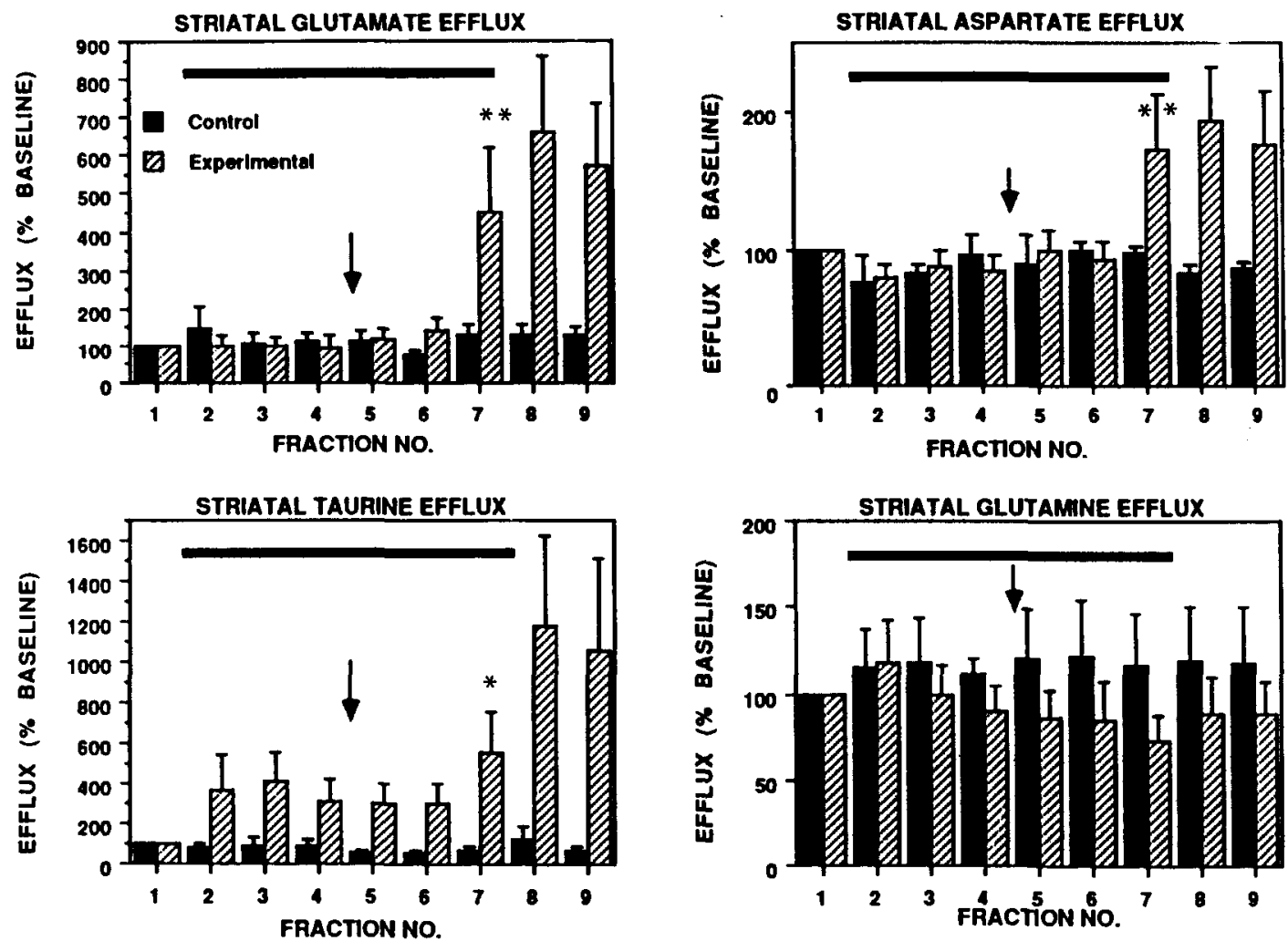

Fig. 1. Graphs demonstrating sequential striatal microdialysis efflux values, expressed as $\%$ of baseline, of glutamate, aspartate, taurine, and glutamine, in animals exposed to $8 \%$ oxygen and perfused with $100 \mathrm{mM} \mathrm{KCl}$ ('Experimental', $n=7$ ) and in controls $(n=3)$. Microdialysis probes, perfused with modified Ringer's solution, were inserted into the right striatum of PND 7 rats (see text for experimental methods). For each animal, baseline values (Fraction 1) were averaged from the first two dialysis samples $(20 \mathrm{~min} / \mathrm{sample})$. Solid horizontal bars indicate period of exposure to $8 \%$ oxygen (Fractions 2-7). Arrow indicates initiation of perfusion with $100 \mathrm{mM} \mathrm{KCl}$ containing solution, ${ }^{*} P=0.017,{ }^{\circ} P=0.053$, Mann-Whitney $U$-test comparing peak efflux values in experimental and control animals.

increased (to $448 \pm 171$ and $173 \pm 41 \%$ of baseline, respectively). These increases were sustained over the next $40 \mathrm{~min}$, while the $\mathrm{KCl}$ infusion was continued in room air. Taurine efflux increased concurrently. The magnitude and timing of maximal stimulation varied considerably; peak increases, for glutamate, aspartate and taurine were $682 \pm 187 \%, 228 \pm 32 \%$, and $1208 \pm 437 \%$ of baseline ( $P=0.017,0.017$, and 0.053 , respectively, comparing peak values, expressed as $\%$ of baseline, in experimentals and controls with Mann-Whitney $U$-tests). In these samples GABA was not consistently detected, and efflux could not be analyzed. A trend towards declines in glutamine efflux was apparent (Fig. 1); depletion of glutamine, a glutamate precursor, could reflect stimulated glutamate efflux, or inhibition of glutamine synthetase. Glycine, serine, alanine, and asparagine efflux were unaffected by hypoxic exposure or $\mathrm{KCl}$ infusion.

An obvious question is whether depolarizing concentrations of $\mathrm{KCl}$ were attained in the first $40 \mathrm{~min}$ of the infusion; since, with the same methods, a $>8$-fold rise in dopamine efflux was observed within $20 \mathrm{~min}$ [8] it is likely that $\mathrm{KCl}$ concentrations in striatum were sufficient to elicit depolarization. Although the long sampling period required for these studies may have obscured subtle or transient stimulation of EAA release, it is more likely that other factors accounted for the initial unresponsiveness to $\mathrm{KCl}$.

The ECF content of EAA is derived from 3 sources: neuronal neurotransmitter pools, neuronal metabolic pools, and glia. At this developmental stage, the concentration of functionally responsive glutamatergic nerve terminals [4] and the amount of neurotransmitter released/neuron may be lower than in the mature brain. If the neurotransmitter pool yielded a relatively small contribution to EAA efflux as compared with metabolic pools, then even with stimulation of neurotransmitter release, little change in total ECF content might be detected. The relatively larger ECF volume in immature brain might contribute an important dilutional effect. Furthermore, depolarization-evoked EAA release from glia may be considerably lower at this developmental stage than in mature brain [14]. These factors, in combination, provide the most likely explanation for our results.

Of note, consistent with results in adult brain [14], sustained depolarization did eventually elicit selective sti- 
mulation of glutamate, aspartate, taurine, and perhaps, GABA release. Relatively low reuptake rates [4] may have contributed to the gradual accumulation of these amino acids. The greater magnitude of $\mathrm{KCl}$-evoked EAA release after hypoxia may, in part, reflect depolarization of a larger number of neurons with more prolonged exposure. However, comparison of EAA efflux at corresponding time intervals of $\mathrm{KCl}$ infusion indicated that values were more consistently elevated in hypoxic animals. Previously, we found that hypoxic exposure markedly increased the magnitude of $\mathrm{KCl}$-stimulated dopamine release (to $>25$-fold)[6]. Contributing mechanisms in both instances could include increased size of the releasable pool (as a result of decreased impulse flow during hypoxia), increased synthesis or intracellular translocation to releasable pools, or hypoxiainduced suppression of re-uptake [15].

Prominent increases in taurine efflux occurred concurrently with stimulation of glutamate efflux. In the immature striatum, both hypoglycemia and hypoxia-ischemia stimulated striatal taurine efflux to a similar extent [7, 13]. It is uncertain if the increased taurine efflux represents an adaptive response to increased glutamate release $[12,13]$, or an independently regulated event.

Our results suggest that at this developmental stage, a substantial fraction of basal striatal ECF EAA content may be derived from non-neurotransmitter pools. If the neurotransmitter pool contributes less to EAA efflux, then detection of depolarization-evoked EAA release with in vivo microdialysis may be considerably more difficult than in adult brain. These observations should be considered in analyzing data from microdialysis studies of amino acid efflux in immature rodent brain.

Supported by USPHS Grants NS01171 and 26142 (to F.S.S).

1 Benveniste, H., Drejer, J., Schousboe, A. and Diemer, N.H., Elevation of the extracellular concentrations of glutamate and aspartate in rat hippocampus during transient cerebral ischemia monitored by intracerebral microdialysis, J. Neurochem., 43 (1984) 13691374.

2 Benveniste, H., Jorgensen, M.B., Sandberg, M., Christensen, T., Hagberg, H. and Diemer, N.H., Ischemic damage in hippocampal $\mathrm{CA} 1$ is dependent on glutamate release and intact innervation from CA3, J. Cereb. Blood Flow Metab. 9 (1989) 629-639.

3 Butcher, S.P., Sandberg, M., Hagberg, H. and Hamberger, A . Cellular origins of endogenous amino acids released into the extracellular fluid of the rat striatum during severe insulin-induced hypoglycemia, J. Neurochem., 47 (1987) 722-728.

4 Campochiaro, P. and Coyle, J. Ontogenetic development of kainate neurotoxicity: correlates with glutamatergic innervation, Proc. Natl. Acad. Sci. U.S.A., 75 (1977) 2025-2029.
5 Donzati, B.A. and Yamamoto, B.K., An improved and rapid HPLC-EC method for the isocratic separation of amino acid neurotransmitters from brain tissue and microdialysis perfusates, Life Sci., 43 (1988) 913-022.

6 Fagg, G.E., Lane, J.D., The uptake and release of putative amino acid neurotransmitters, Neuroscience, 4 (1979) 1015-1036.

7 Globus, M.Y., Busto, R., Dietrich, W.E., Martinez, E., Valdes, I. and Ginsberg, M.D., Effect of ischemia on the in vivo release of striatal dopamine, glutamate and GABA studied by intracerebral microdialysis, J. Neurochem., 51 (1988) 1455-1464.

8 Gordon, K., Statman, D., Johnston, M.V., Robinson, T.E., Becker, J.B. and Silverstein, F.S., Transient hypoxia alters striatal catecholamine metabolism in immature brain: An in vivo microdialysis study, J. Neurochem., 54 (1990) 605-611.

9 Gordon, K., Simpson, J., Statman, D. and Silverstein, F.S., Perinatal hypoxic-ischemic brain injury alters striatal amino acid efflux in rat brain : an in vivo microdialysis study, Soc. Neurosci. Abstr., (1990) 386.6.

10 Hagberg, H., Lehmann, A., Sandberg, M., Nystrom, B., et al., Ischemia-induced shift of inhibitory and excitatory amino acids from intra- to extracellular compartments, J. Cereb. Blood Flow Metab., 5 (1985) 413-419.

11 Hillered, L., Hallstrom, A., Segersvard, S., Persson, L. and Ungerstedt, U., Dynamics of extracellular metabolites in the striatum after middle cerebral artery occlusion in the rat monitored by intracerebral microdialysis, J. Cereb. Blood Flow Metab., 9 (1989) $607-$ 616.

12 Lehmann, A., Hagberg, H. and Hamberger, H., A role for taurine in the maintenance of homeostasis in the CNS during hyperexcitation? Neurosci. Lett., 52 (1984) $34-36$.

13 Menendez, N., Herreras, O., Solis, J.M., Herranz, A.S. and del Rio, M.R., Extracellular taurine increase in rat hippocampus evoked by specific glutamate receptor activation is related to the excitatory potency of glutamate agonists, Neurosci. Lett., 102 (1989) 64-9.

14 Paulsen, R.E. and Fonnum, F., Role of glial cells for the basal and $\mathrm{Ca}^{++}$-dependent $\mathrm{K}^{+}$-evoked release of transmitter amino acids investigated by microdialysis, J. Neurochem., 52 (1989) 1823-1829.

15 Silverstein, F.S., Buchanan, K. and Johnston, M.V., Perinatal hypoxia-ischemia disrupts striatal high affinity ${ }^{3} \mathrm{H}$-glutamate uptake into synaptosomes, J. Neurochem., 47 (1986) 1614-1619.

16 Silverstein, F.S., Simpson, J. and Gordon, K., Hypoglycemia alters striatal amino acid efflux in perinatal rats: an in vivo microdialysis study, Ann. Neurol., 28 (1990) 516-521.

17 Ungerstedt, U., Measurement of neurotransmitter release by intracranial dialysis. In C.A. Marsden (Ed.), Measurement of Neurotransmitter Release in vivo, Wiley, New York, 1984, pp. 81107.

18 Westerink, B.H., Damsma, G., Rollema, H., De Vries, J.B. and Horn, A.S., Scope and limitations of in vivo brain dialysis: a comparison of its application to various neurotranstter systems, Life Sci., 41 (1987) 1763-76.

19 Young, A.M.J. and Bradford, H.F., Excitatory amino acid neurotransmitters in the corticostriate pathway: studies using intracerebral microdialysis in vivo, J. Neurochem., 47(1986) 1399-1404. 